\title{
LIVROS NOVOS DE GEOGRAFIA FÍSICA
}

A editorial Masson \& Cie, de Paris, acaba de lançar, na sua colecção de compêndios didácticos, Principes et Méthodes de la Géomorphologie, um volume de 496 páginas da autoria do Professor JEAN TRICART, da Universidade de Estrasburgo e Director do Centro de Geografia Aplicada da mesma Universidade. A abrir o livro o autor informa: «São vinte anos de trabalho sem descanso, apresentado ao público científico sob a forma de um esforço destinado a ajudar todos os que desejarem empreender investigações pessoais ou fazer uma ideia dos princípios de uma disciplina vizinha. Este livro dirige-se, com efeito, aos que praticam activamente as Ciências da Terra. Aos especialistas das disciplinas conexas permitirá compreender o que é a geomorfologia, quais são os seus problemas, quais são os seus métodos, que resultados ela lhes pode oferecer. AOs geomorfólogos, ajudará a compreender melhor a sua disciplina, a sua lógica interna, os seus conceitos fundamentais. Oferecer-lhes-á um fio condutor sintético para não se perderem na proliferação das técnicas e na dispersão dos resultados. A sua ambição é facilitar-lhes o acesso à nossa disciplina, primeiro à sua compreensão, em seguida à sua prática».

A obra está dividida em quatro grandes partes, ou livros, por sua vez subdivididos em vários capítulos. Os títulos daqueles são: Livro I Qual deve ser a orientação da Geomorfologia (pp. 15-76); Livro IIobservação dos fenómenos e dos factos geomorfológicos (p̣p. 77-242); Livro III - A análise dinâmica: o estudo dos mecanismos (jp. 243-396) Livro IV - O estudo do passado em Geomorfologia: evoluções, reconstituições paleogeográficas (pp. 397-469). No final de cada «livro» há algumas páginas de referências bibliográficas. A obra é rematada com uma Conclusão Geral (pp. 471-475), antes dos índices dos autores, de nomes técnicos, de figuras e de matérias.

E mais uma tentativa de aproximação metodologica em Geomorfologia, a mais recente de uma série que já conta com outros trabalhos como os de S. PASSARge, Physiologische Morphologie (1912); de A. HeTTNER, Die Oberflachenformen des Festlandes (1921); de W. PENCK, Morphologische Analyse (1921); de P. BIRoT, Les Méthodes de la Morphologie (1955), que traduzem sobretudo conceitos pessoais dos autores. 
Da mesma editora, com datas de 1964 e 1965 respectivamente, sảo os manuais de L. Lliboutry, Traité de Glaciologie (tome I - Glace, Neige, Hydrologie Nivale) e de A. GulLcher, Précis d'Hydrologie Marine et Continentale.

O primeiro livro referido veio preencher uma lacuna importante, pois o tratado mais moderno de glaciologia, escrito em russo por KALESNIK, datava de 1939 e não estava traduzido em línguas ocidentais. Num volume de 427 páginas, ilustrado com numerosas figuras e estampas, as matérias (já está anunciado o tomo II-Glaciers. Variations de climat. Sols gelés) estão apresentadas em onze capítulos, depois de uma introdução histórica sobre o desenvolvimento da glaciologia, definição do seu campo e métodos de trabalho. Os títulos dos capítulos são os seguintes: I - Física do gelo; II - Propriedades mecânicas do gelo; III - Petrografia do gelo; IV - Gelo de água doce e do mar; V — Os hidrometeoros; VI - Evolução do manto nival; VII - Propriedades mecânicas da neve; VIII - A neve em engenharia civil; IX --Variações térmicas na superfície e escoamento; $\mathbf{X}$ - Formas de ablação e de regelo; $\mathrm{XI}-T e m p e r a t u r a s$ na neve e nos glaciares. No fim de cada capítulo vêm numerosos títulos de bibliografia escolhida, actualizada, porquanto são muitos os trabalhos de 1963. O autor é professor da Universidade de Grenoble, que tanto tem contribuido para o conhecimento geográfico e geológico dos Alpes.

O geógrafo, em especial o geomorfólogo, encontrará, para além da dificuldade de penetração da formulação física e matemática de muitos dos assuntos tratados, numerosas páginas de interesse sobre problemas de escoamento dos inlandsis; do movimento dos glaciares de vale; sobre aspectos da reacção dos glaciares às flutuações aleatórias estacionárias do clima; sobre a origem das moreias de base; o estudo de certas formas periglaciais; a descrição de formas de regelo; etc., etc.

Juntamente com Le Modelé Glaciaire et Nival, de I. TRICART e A. CaIlleux (ed. S. E. D. E. S., Paris, 1962, vol. de 508 pp.), e Géomorphologie des Régions Froides de J. TrICART (ed. P. U. F., Paris, 1963, vol. de $289 \mathrm{pp}$.) os especialistas da Geomorfologia glaciária têm assim bases valiosas de estudo e apoio para as suas investigações.

O segundo livro, do Professor André Gurlcher, que tem ensinado hidrologia maritima e fluvial na Sorbonne, é um volume de 389 páginas, profusamente ilustrado (217 figuras). O conjunto de matérias, após a Introdução, distribui-se por três secções, divididas em vários capítulos. Primeira secção - Hidrologia marítima (pp. 5-240). O autor abre a exposição da matéria com uma breve sintese histórica-- Os meios e os métodos de investigação; Segunda secção — Hidrologia lacustre (pp. 241. -263); Terceira secção-Hidrologia fluvial (pp. 264-376). No fim do trabalho, um «Apêndice» tem por título Ensaio de representação cartográfica dos regimes fluviais estacionais no Mundo (pp. 377-379), e inclui um mapi-mundo (fig. 217) com a representação convencional de 13 regimes fluviais. Nu fim de cada capítulo vem uma lista de trabalhos de orientação bibliográfica.
De acordo com a informação do autor, o objectivo deste Précis é de oferecer uma mise au point do grande desenvolvimento da oceanografia desde 1945, dos progressos consideráveis da hidrologia fluvial especialmente para uso dos geógrafos, que passarão assim a dispor de um meio de documentação sintética e de volume limitado. Para tal foram postas de parte as noções e problemas pròpriamente técnicos, bem como o conjunto do aparelho matemático, indispensáveis, é evidente, para o progresso daquelas disciplinas, mas que se podem dispensar para a apresentação geral dos resultados adquiridos. Da mesma forma a parte instrumental foi reduzida ao minimo.

A propósito deste Précis de A. GUILcher recordamos o volume policopiado das lições de RENÉ FRECAUT, Assistente da Faculdade de Letras e Ciências Humanas de Nancy, publicado pelo Centre de Documentation Universitaire, Paris, 1964: Eléments d'Hydrologie Continentale (231 páginas).

ILIDIO DO AMARAL 